\title{
Review
}

\section{Potential roles of mesenchymal stem cells and their exosomes in the treatment of COVID-19}

\author{
Xiaoyun Cheng ${ }^{1}$, Mao Jiang ${ }^{2}$, Lingzhi Long ${ }^{2}$, Jie Meng ${ }^{2, *}$ \\ ${ }^{1}$ Department of Pulmonary and Critical Care Medicine, Xiangya Hospital of Central South University, 410008 \\ Changsha, Hunan, China, ${ }^{2}$ Department of Pulmonary and Critical Care Medicine, The Third Xiangya Hospital of Central \\ South University, 410008 Changsha, Hunan, China
}

\section{TABLE OF CONTENTS}

1. Abstract

2. Introduction

3. MSCs regulate immune cells in COVID-19

3.1 MSCs interfere with the differentiation, maturation, and function of antigen-presenting cells (APCs) in COVID-19

3.2 MSCs regulate the polarization of macrophages in COVID-19: from M1 to M2

3.3 MSCs regulate lymphocyte subsets and apoptosis in COVID-19

4. MSCs improve ARDS in COVID-19

5. MSCs promote lung regeneration and reverse PF in COVID-19

6. MSC-exosomes for the treatment of COVID-19

6.1 Comparison of MSC-exosomes and MSCs

6.2 Unique advantages of MSC-exosomes over MSCs for COVID-19 treatment

7. Clinical trials of MSCs and MSC-exosome therapy for COVID-19

8. Conclusions

9. Author contributions

10. Ethics approval and consent to participate

11. Acknowledgment

12. Funding

13. Conflict of interest

14. References

\section{Abstract}

Background: Corona Virus Disease 2019 (COVID-19) is an acute respiratory infectious disease caused by severe respiratory syndrome coronavirus 2 (SARS-CoV-2). The primary pathogenesis is overactivation of the immune system. SARS-CoV-2 continues to mutate and spread rapidly and no effective treatment options are yet available. Mesenchymal stem cells (MSCs) are known to induce anti-inflammatory macrophages, regulatory $\mathrm{T}$ cells and dendritic cells. There are a rapidly increasing number of clinical investigations of cell-based therapy approaches for COVID-19. Objective: To summarize the pathogenic mechanism of SARS-CoV-2, and systematically formulated the immunomodulation of COVID-19 by MSCs and their exosomes, as well as research progress. Method: Searching PubMed, clinicaltrials.gov and Chictr.cn for eligible studies to be published or registered by May 2021. Main keywords and search strategies were as follows: ((Mesenchymal stem cells) OR (MSCs)) AND (COVID-19). Results: MSCs regulate the immune system to prevent cytokine release syndrome (CRS) and to promote endogenous repair by releasing various paracrine factors and exosomes. Conclusions: MSC therapy is thus a promising candidate for COVID-19.

\section{Introduction}

According to real-time WHO network data, the worldwide number of confirmed COVID-19 cases to April 22, 2021 was 143,488,236 and 3,055,587 deaths, posing an unprecedented threat to the global economy and to human health [1]. The International Committee on the Taxonomy of Viruses named the COVID-19 pathogen as SARS-CoV2. This virus gains phagocytic entry into AT2 via interaction with angiotensin-converting enzyme 2 (ACE2) (See Fig. 1). It increases Angiopoietin-2 (Ang-2) levels, lead- 


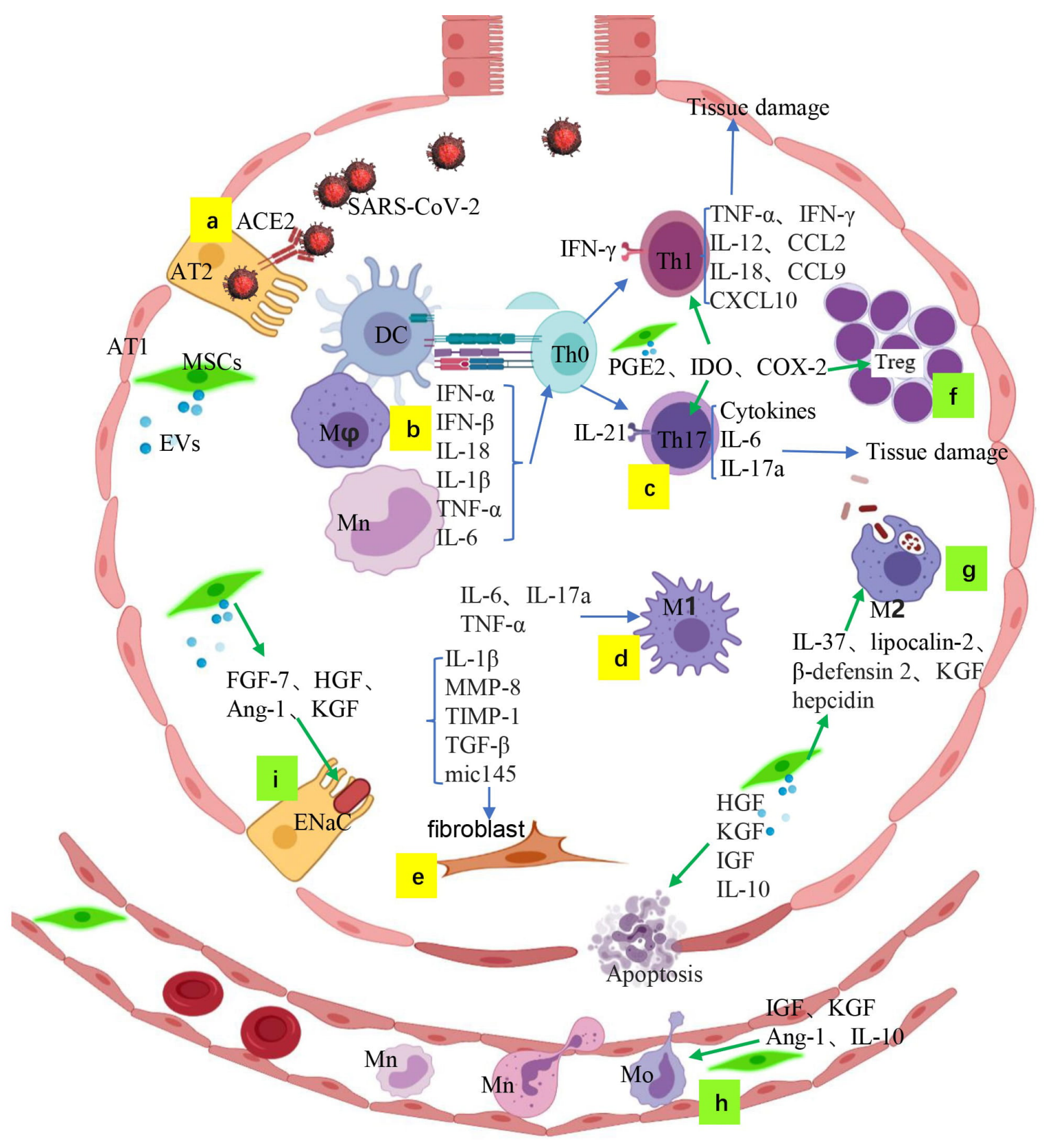

Fig. 1. The pathological processes of COVID-19 (blue arrows) and multiple therapeutic mechanisms of MSCs and their exosomes in COVID-19 (green arrows). (a) SARS-CoV-2 gains entry into AT2s via ACE2. (b) Immune cells recognize SARS-CoV-2 via TLRs. (c) T cells are polarized into pro-inflammatory phenotypes. (d) Excessive activation of M1 causes CRS. (e) Inflammation and oxidative damage cause lung fibrosis and remodeling. MSCs reduce fibrosis by various paracrine factors. (f) MSCs force T cells to polarize into Tregs. (g) MSCs and MSC-exosomes increase the number of anti-inflammatory M2 macrophages. (h) MSCs restore microvascular permeability. (i) MSCs activate the $\mathrm{Na}+\mathrm{K}+$ pump to remove lung fluid and reduce pulmonary edema. Abbreviations: ECM, extracellular matrix; PGE 2, Prostaglandin E 2; COX, Cyclooxygenase; HGF, hepatocyte growth factor; KGF, keratinocyte growth factor.

ing to long-term and intense activation of pro-inflammatory Ras-related pathways. A high concentration of Ang-2 in the lung interstitium promotes cell apoptosis, releases proinflammatory cytokines and triggers the inflammatory response, thereby causing immune-induced tissue damage and increased vascular permeability [2, 3]. In patients with severe disease, the development of CRS is an abnormal systemic inflammatory response that manifests clinically as a rapid and sharp rise in the level of cytokines. These include C-X-C Motif Chemokine Ligand 10 (CXCL10), monocyte chemo-attractant protein-1 (MCP-1/CCL2), macrophage inflammatory protein-1 (MIP-1), platelet-derived growth factor (PDGF), tumor necrosis factor- $\alpha$ (TNF- $\alpha$ ) and vascular endothelial growth factor (VEGF) [4]. This mechanism results in an imbalance between tissue damage and repair, leading to respiratory failure. Patients may eventu- 
Table 1. The potential roles and mechanisms of MSC-exosomes in various diseases.

\begin{tabular}{|c|c|c|c|}
\hline Functions & Involved genes/factors/pathways & Diseases & References \\
\hline $\begin{array}{l}(+) \text { Immunomodulatory activities (+) re- } \\
\text { pair (+) angiogenesis (-) fibrosis }\end{array}$ & $\begin{array}{l}\text { miR-21, miR-24, miR-124, miR-145, miR-122, KGF, } \\
\text { VEGF, HGF, VE-cadherin, Occludin-1, Claudin-1, PCNA, } \\
\text { Cyclin D1, IDO, Wnt } / \beta \text {-catenin signalling, TGF- } \beta 1 / \text { Smad } 2\end{array}$ & COVID-19 & [17-22] \\
\hline (-) EMT & miR-182-5p, miR-23a-3p (-) NF-кB, Hedgehog & LPS induced lung injury & [23] \\
\hline (-) Inflammation, proliferation & miR-34a, miR-122, miR-124, miR-127 & IPAH & [24] \\
\hline (-) Leukocyte infiltration & ICAM-1 & ARDS & [25] \\
\hline Anti-viral & COX-2, PGE2 & Influenza & [26] \\
\hline (-) Airway hyperresponsiveness & miR-146a-5p & Allergic airway inflammation & [27] \\
\hline (-) Autophagy, apoptosis & $\begin{array}{l}\text { miR-125b, Bcl-xL, Bcl2, and BIRC8 (-) Caspase1, Caspase } \\
\text { 8, lymphotoxin } \alpha\end{array}$ & $\begin{array}{l}\text { Myocardial infarction, acute } \\
\text { kidney injury. }\end{array}$ & {$[28,29]$} \\
\hline$(-)$ Fibrosis & (-) Col-I, Col-III, TGF- $\beta 1 /$ Smad & Liver fibrosis & {$[30,31]$} \\
\hline$(+)$ M2 macrophage polarization & miR-1260b (-) Wnt5a/RANKL & Periodontitis, Tendon healing & {$[32,33]$} \\
\hline (+) Treg cell induction, T-cell apoptosis & FASL/FAS & Acute colitis & [34] \\
\hline (-) Dendritic cell maturation & a blockade in G0/G1 phase of the cell cycle & LPS intervention & [35] \\
\hline (+) Autophagy & AMPK//mTOR, Akt/mTOR & Myocardial I/R & [36] \\
\hline
\end{tabular}

$(+)$ indicates stimulation. $(-)$ indicates inhibition.

ally die from multiple organ failure. Disruption of matrix metalloproteinases (MMPs) during the inflammatory stage causes complex damage to the alveolar epithelium and to the pulmonary vascular endothelium [5]. Moreover, persistent stimulation of epithelial cells results in senescencerelated phenotypes. Consequently, abnormal interactions between fibroblasts and epithelial cells generate irreversible damage and fibrosis [6].

Although the efficacy of vaccines in preventing COVID-19 ranges from 50\% to 95\%, an increasing number of COVID-19 cases still require effective treatment options $[7,8]$. There is currently no standard drug therapy for COVID-19. Antiviral, anti-malarial and anti-inflammatory drugs are unable to repair or regenerate lung tissues, especially in patients with severe complications such as acute respiratory distress syndrome (ARDS) [9-11]. Since the outbreak of COVID-19, a number of studies have been carried out on MSCs and MSC-exosome therapy for this disease. MSCs have good safety for the treatment of COVID19 and show particular clinical efficacy in shortening the course of disease, alleviating lung injury and reducing the level of inflammatory factors $[6,12,13]$. This is expected to provide a new approach for the treatment of severe and critical COVID-19. MSC-exosomes also show promise as a cell-free substitute for COVID-19 [14-16] (Table 1, Ref. [17-36]). The potential mechanisms of action of MSCs and MSC-exosome therapy are shown in Figs. 1,2.

\section{MSCs regulate immune cells in COVID-19}

3.1 MSCs interfere with the differentiation, maturation, and function of antigen-presenting cells (APCs) in COVID-19

Once SARS-CoV-2 infects the human lung epithelium and is internalized (Fig. 1a), SARS-CoV-2 RNA acti- vates the intracellular receptors TLR3/7 and membrane receptors TLR2/4. TLR3 in dendritic cells (DCs) specifically recognize dsRNA, an intermediate product of viral replication, thereby activating nuclear factor kappa-B (NF- $\kappa \mathrm{B})$ and interferons (IFNs). TLR2 and TLR4 located on the surface of macrophages and DCs can activate interferon regulatory factors (IRFs) and NF- $\kappa \mathrm{B}$, resulting in the production of different cytokines and chemical activators. TLR2 can mediate DCs to express interleukin-8 (IL-8) and IL-23 (Fig. 2b), while TLR4 mainly mediates DCs to produce IL12 and IFN- $\gamma$-induced protein 10 (IP-10). IP-10 in turn stimulates $\mathrm{T}$ cells to secrete IFN and promotes the differentiation of T helper-type (Th) cells into Th1 cells (Fig. 1c) [24].

MSCs can interfere with the antigen-presenting function, differentiation and maturation of DCs by paracrine IFN- $\gamma$, indoleamine 2,3-dioxygenase (IDO), transforming growth factor- $\beta$ (TGF- $\beta$ ), IL-10 and prostaglandin E2 (PGE2) [37]. Consequently, this reduces the activation of DCs and their pro-inflammatory secretions [38, 39]. Leng et al. [40] observed a significant increase in the number of CD14+CD11c+CD11 ${ }^{\text {mid }}$ low-activity phenotypic DCs on day 6 after MSC transplantation. This prevented the excess proliferation of T cells in COVID-19 patients. The interaction between MSCs and DCs also leads to an indirect conversion of pro-inflammatory Th1 to anti-inflammatory Th2 immunity [41].

3.2 MSCs regulate the polarization of macrophages in COVID-19: from M1 to M2

Pro-inflammatory macrophages were reportedly more abundant in the bronchoalveolar lavage fluid from severe compared to mild COVID-19 cases [42]. Zhang et al. [43] proposed that CRS in severe COVID-19 is mainly a virus-triggered macrophage activation syndrome. Viral RNA stimulates macrophages to produce various soluble 

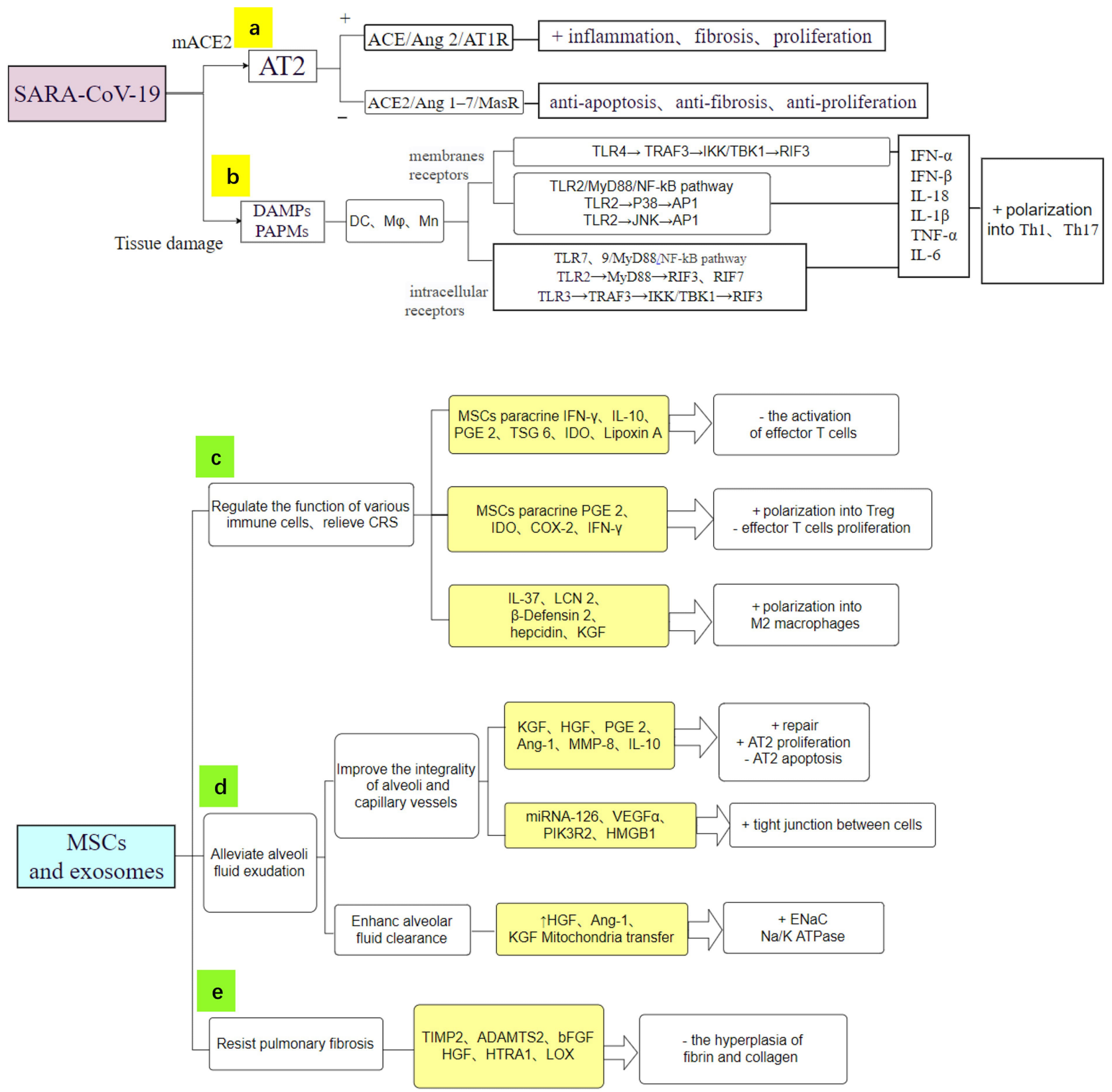

Fig. 2. MSCs act on COVID-19 through multiple mechanisms and specific secretory products (light yellow squares). (a) SARS-CoV-2 causes immune-induced tissue damage via pro-inflammatory Ras-related pathways. (b) TLRs of immune cells recognize SARS-CoV-2, leading to CRS. (c) MSCs have powerful anti-inflammatory and immunomodulatory functions. (d) MSCs repair microvascular permeability and alleviate pulmonary edema. (e) MSCs secrete substances to inhibit the hyperplasia of fibrin and collagen, thereby alleviating PF. + indicates stimulation. - indicates inhibition.

factors via the activation of TLRs. These factors include IFN- $\gamma$, IP10, MCP1, MIP10, granulocyte colony stimulating factor (G-SCF), IL-2, IL-6, IL-7 and TNF- $\alpha$. In particular, IL-6 and TNF- $\alpha$ cause macrophages to differentiate into M1 (Fig. 1d), thus causing an imbalance in M1/M2. In addition to direct stimulation by viral RNA, ATP is released by the dead cells as DAMPs and binds to the P2X7 receptor (P2X7R). This in turn activates NODlike receptor protein 3 (NLRP3) inflammasomes and increases macrophage-derived IL-1 $\beta$ and IL-18 [37]. The loss of alveolar macrophages is a major underlying cause of refractory respiratory failure in COVID-19 and it has been reported they are almost entirely depleted in severely infected patients [44].

MSCs regulate macrophage polarization to limit inflammation and to promote tissue healing following injury. Anti-inflammatory soluble factors and two main inhibitory molecules secreted or expressed by MSCs trigger the immune system's inhibitory response. MSCs are stimulated to produce IL-10, thyrotropin-releasing hormone-6 (TRH-6), human leukocyte antigen (HLA), human growth factor (HGF), heme oxygenase-1 (HO-1) [45], superoxide 
dismutase (SOD), cyclooxygenase-2 (COX-2), PGE2 and IDO [46]. Meanwhile, MSCs are induced by IFN- $\gamma$ to upregulate the expression of other inhibitory molecules, including PD-1/PDL-1 and FAS-FASL [47-49]. These soluble factors and molecules inhibit pro-inflammatory pathways such as the NF- $\kappa \mathrm{B}$ signaling pathway and also polarize M1 macrophages into the anti-inflammatory M2 phenotype [50, 51]. In this way, MSCs reduce the production of inflammatory cytokines by macrophages in COVID-19 [52].

3.3 MSCs regulate lymphocyte subsets and apoptosis in COVID-19

Flow cytometry analysis has shown that the number of CD4+ and CD8+T cells in the peripheral blood of COVID-19 patients was significantly reduced, with the degree of reduction being related to the severity of COVID19 [53]. This phenomenon may be related to the recruitment of $\mathrm{T}$ cells from peripheral blood to lung tissue, and to the apoptosis of $\mathrm{T}$ cells induced by the virus [54]. COVID-19 patients present with lymphocyte deficiency and over-activation of $\mathrm{T}$ cells. These effector $\mathrm{T}$ cells are stimulated by pro-inflammatory mediators produced by DCs, macrophages and neutrophils [55, 56]. A significant rise in HLA-DR+CD38+ cell levels can manifest in the over-activation of $\mathrm{T}$ cells. The proportion of highly proinflammatory CCR4+CCR6+ Th17 cells amongst CD4+ T cells then increases [57]. High expression of IL-17A in Th17 induces the migration of inflammatory white blood cells, leading to inflammatory infiltration and destruction of lung tissue. Additionally, the major histocompatibility complex 1 (MHC-1) of infected cells presents viral antigens, thus activating CTLs to produce high levels of cytotoxic granules such as perforin and granzymes. This implies that over-activation of $\mathrm{T}$ cells and the elevated cytotoxicity of CD8+T cells leads to an excessive immune response. $\mathrm{T}$ cell-derived cytokines and chemokines such as TNF- $\alpha$, IFN- $\gamma$, IL-2, IL-12, CCL2, IL-18, CCL9, CXCL10, IL-6 and IL-17 are released in large quantities and damage the lung tissue [58]. When the T cell count falls to its lowest level, the concentrations of serum IL10, IL2, IL4, TNF- $\alpha$ and IFN- $\gamma$ reach their peak on days 4-6. Moreover, the levels of IL-6, IL-7, G-CSF, IP-10, monocyte chemotactic protein-1 (MCP-1) and MIP1a increase significantly, thus causing CRS [59].

Leng et al. [40] reported that on day 4 after MSC transplantation, the absolute lymphocyte count increased to $0.58 \times 10^{9} / \mathrm{L}$ and lymphocytopenia improved significantly. On days 3 to 6 after transplantation, the level of TNF- $\alpha$ decreased whereas that of IL-10 increased. Similar reversals were reported in another study [60]. T cell counts were also analyzed in a non-randomized, open-label cohort study of COVID-19 patients [18]. This indicated that MSCexosome therapy significantly improved the absolute neutrophil count by a mean of $32 \%$ [ $p$ value $<0.001$ ] in patients with severe COVID-19. Moreover, the mean CD3+, CD4+ and CD8+ lymphocyte counts increased by $46 \%(p<0.05)$, $45 \%(p<0.05)$ and $46 \%(p<0.001)$, respectively.

The mechanism of action of MSCs in reversing lymphocytopenia and reducing inflammatory mediators in COVID-19 is mainly attributed to the more than 30 soluble paracrine factors such as PEG2, IDO and COX-2 [61]. These have been shown to inhibit the proliferation of CD4+ Th1 and Th17 cells as well as CD8+T cells, and to induce Foxp3+ Treg differentiation (Fig. 1f). They also indirectly inhibit excessive $\mathrm{T}$ cell proliferation by interacting with APCs and other immune cells. IL-10 is a critical negative regulator of $\mathrm{T}$ cell responses and directly inhibits the ability of $\mathrm{T}$ cells to produce pro-inflammatory mediators. IL-10 also reduces the antigen presenting capacities and co-stimulation of macrophages and DCs, thereby decreasing T cell-derived IL-6 and TNF- $\alpha$, which is one of the essential mechanisms by which MSCs alleviate inflammation [62, 63]. This was demonstrated in a recent clinical report by Meng et al. [64] which showed that patients who received MSCs had lower IL-6 levels than those who received placebo [65].

Through their expression of PD-L1 and FasL, MSCs can inhibit abnormally activated Th1 cells, thus inhibiting IL- $\gamma$ release from Th1. This prevents further macrophage activation in a vicious loop and restores Th1/Th2 balance. Long-term FasL interaction can induce apoptosis of cytotoxic T cells [66].

At the same time, MSCs release TGF- $\beta$ which promotes the proliferation of CD4(+) CD25(+) FoxP3(+) Treg, CD3(+) CD8(+) CD28(-) T-suppressor cells (Ts), and IL10-producing B cells [67]. MSCs also up-regulate IDO and PGE2, which have synergistic inhibitory effects on NK and Th17 cells. MSCs inhibit B cells through cell cycle stagnation in the G0/G1 phase rather than by inducing apoptosis. With regard to cellular immunity, MSCs reduce the production of immunoglobin M (IgM), IgG, and IgA, and downregulate the expression of CXCR4, CXCR5 and CXCR7 in B cells, thereby altering their chemotactic properties [68].

\section{MSCs improve ARDS in COVID-19}

ACE2 is down-regulated following the entry of SARS-CoV-2 into alveolar epithelial cells, resulting in an imbalance of ACE/Ang II/AT1R and ACE2/Ang 17/MASR. Elevated Ang-2 levels then lead to cell apoptosis and trigger inflammatory responses, giving rise to immuneinduced tissue damage and increased vascular permeability [69-71] (Fig. 2b).

In COVID-19 patients the average time from symptom onset to dyspnea is 5 days, the average hospital stay is 7 days, and the average time for onset of ARDS is 8 to 9 days [72]. By day 8 to 14 of disease onset, the overexpression of cytokines such as IL-2, IL-6, IL-7, IP10, MCP1, MIP1A and TNF $\alpha$ causes activation of lympho- 
cytes and macrophages, leading to an excessive inflammatory response [73]. The integrity of alveolar walls and pulmonary capillaries are destroyed, resulting in edema that impairs oxygen exchange and respiration and inevitably develops into ARDS [74, 75].

MSCs and MSC-exosomes can effectively alleviate COVID-19-induced ARDS in a dose-dependent manner by increasing alveolar fluid clearance and by improving airway and hemodynamic parameters [76]. MSC-exosomes have been used as intravenous infusion therapy for ALI and pulmonary fibrosis (PF) [23, 77, 78]. An earlier study showed the exosomes release keratinocyte growth factor (KGF) and Lipoxin A4 which act to prevent long-term lung damage caused by COVID-19 and to promote tissue repair by activating $\mathrm{Na}+/ \mathrm{K}+$ pumps [79] (Fig. 2d). Importantly, MSCs have been shown to restore epithelial protein permeability, stabilize endothelial fluid leakage, and maintain alveolar-capillary barrier function by secreting Ang-1 [80-82]. In addition, MSCs can inhibit cellular signaling pathways mediated by TLRs or PRRs, as well as reducing local immune cell recruitment (Fig. 2c). miRNA-126, VEGF- $\alpha$, phosphoinositide-3-kinase regulatory subunit 2 (PIK3R2) and high mobility group box chromosomal protein 1 (HMGB1) can each restore the vascular endothelial cadherin-catenin (VE-Cadherin) complex and reduce endothelial barrier permeability to relieve ARDS.

\section{MSCs promote lung regeneration and reverse $\mathrm{PF}$ in COVID-19}

PF is a refractory lung disease that develops due to persistent alveolar injury, repeated destruction, repair, reconstruction, and excessive deposition of extracellular matrix (ECM) [83]. Current studies have determined that only $1 \%$ of AT2 cells can regenerate following SARS-CoV-2induced lung injury [84, 85].

High expression of IL-17A by Th17 in COVID19 can induce the migration of inflammatory leukocytes, leading to inflammatory infiltration and the destruction of lung tissue [86]. High levels of TNF- $\alpha$ induce the recruitment of immune cells and reduce antioxidant molecules in parenchymal and endothelial cells, causing lung fibrosis and remodeling (Fig. 1e). MSCs improve angiogenesis mainly through paracrine release of pro-angiogenic/antiapoptotic agents such as Ang, IL-3, MMP-1 and VEGF [87]. They also secrete ECM regulators such as fibroblast growth factor, HGF and MMPs to regenerate damaged tissues [88]. Moreover, MSCs express or secrete ADAM, metallopeptidase with thrombospondin Type 1 Motif 2 (ADAMTS2), basic fibroblast growth factor (bFGF), collagen 15A1 (COL15A1), COL16A2, COL18A1, HGF, high temperature requirement A1 (HTRA1), lipoxygenase (LOX), and tissue inhibitor of metalloproteinases 2 (TIMP2). These regulate the expression of collagen, fibronectin and elastin fibrilaments in lung tissue, thereby alleviating PF [89]. MSCs can also reverse PF by overexpressing MMP-P1 and decreasing collagen-1 (COL-I) production during TGF- $\beta 1$-induced fibrosis. In conclusion, MSCs can promote angiogenesis and the regeneration of alveolar epithelial cells, prevent the apoptosis of endothelial cells, reduce the levels of TGF- $\beta$, TNF- $\alpha$, COL-I, COL-III, Hydroxyproline and serum ceruloplasmin, inhibit myofibroblast growth, and thereby alleviate or reverse PF (Fig. 2e).

Human embryonic stem cells (hESCs) derived from immune and stromal regulatory cells (IMRCs) have been used to treat lung injury and fibrosis in vivo. IMRCs have superior efficacy to FDA-approved pirfenidone [14] and show excellent efficacy and safety in both mice and monkeys [90].

\section{MSC-exosomes for the treatment of COVID-19}

MSC-exosomes are able to transfer cargoes such as mRNA, miRNA, proteins, lipids and even mitochondria to target cells and tissues, resulting in changes to gene expression and in the behavior of target cells. Hence, MSC-exosomes could have a therapeutic role in COVID19 [91, 92]. Preclinical studies have confirmed that MSCexosomes are able to serve as acellular alternatives [78].

\subsection{Comparison of MSC-exosomes and MSCs}

\subsubsection{Can MSC-exosomes effectively replace MSCs?}

A growing number of studies have established that the healing, nutritional, immunoregulation, and antiinflammatory effects of administered MSCs are due to the exosomes they release. These effects of MSCs have been observed in vitro after the addition of MSC-exosomes [37]. MSCs were cleared from the circulation within 24 hours, but MSC-exosomes were detected in lung parenchymal cells and macrophages just 1 hour after injection and remained there for up to 7 days [93]. The efficacy and safety of a single intravenous injection of MSC-exosomes were recently assessed in 24 COVID-19 patients who presented with moderate to severe ARDS. The clinical symptoms, oxygenation, serum markers of acute inflammation, neutrophil and lymphocyte counts all improved in patients who received MSC-exosomes, with no side effects reported [18].

The immunomodulatory effects of MSCexosomes have also been attributed to their antiinflammatory cargo, such as IDO, HLA-G, PD-L1, galectin-1, IL-10, TGF- $\beta 1$ and HGF. These factors inhibit IL-1, IL-6, NK cells, effector and cytotoxic T cells, while activating M2 macrophages and Treg to further suppress the over-activated immune system [94, 95]. Importantly, MSC-exosomes also transfer miRNAs that play a role in COVID-19, including miRNA-145, miRNA-126, miRNA199a, miRNA-221, miRNA-27 and Let-7f [88, 96, 97]. In coronavirus pneumonia and influenza, mi-RNAs carried by 
MSC-exosomes inactivate cytoplasmic mRNA encoding proteins and change nuclear DNA through methylation [26]. Thus by changing the expression of cell receptors and directly preventing the entry of RNA viruses. In addition, MSCs have comparable immunoregulatory activity.

MSC-exosome-transferred miRNAs cause APCs to produce fewer Ag/MHC molecules on their surface, thus resulting in reduced activation of effector $\mathrm{T}$ cells. miRNAs carried by MSC-exosomes also mediate the function of macrophages, NK cells, T cells and B cells to inhibit infection [98].

\subsubsection{MSC-exosomes are safer than MSCs for COVID-19 treatment}

In the context of COVID-19, MSCs are known to aggregate in the peripheral microvasculature and exacerbate vascular clots, causing central or peripheral vascular dysfunction. This is probably because MSCs express procoagulant tissue factor (TF/CD142) on their surface $[99,100]$.

The small size and low immunogenic effect of MSC-exosomes allows them to pass through small blood capillaries without triggering a blood clot [101]. Because of their strong ability for self-replication and differentiation, the carcinogenicity of MSCs is also another clinical challenge. MSC-exosomes cannot replicate and hence there is no risk of endogenous tumor formation [102].

\subsection{Unique advantages of MSC-exosomes over MSCs for COVID-19 treatment}

\subsubsection{Advantages of MSC-exosomes for COVID-19: practical considerations}

The challenges surrounding the use of MSCs for COVID-19 that still need to be overcome include their immuno-compatibility, stability, heterogeneity, differentiation and migration. The low homing rate of MSCs is also the focus of current research. Although Xiao et al. raised the possibility that CD90 binding to the specific integrins b3 and b5 could to some extent promote MSC homing [103], MSC-exosomes have an important advantage in their homing ability. Due to their nanosized dimension, intravenously injected MSC-exosomes accumulate in COVID19-damaged organs through blood circulation [104]. MSCexosomes from allogenic sources can also be used immediately after thawing and without washing. In addition, MSCexosomes are easier to use routinely in hospitals compared to MSCs. Finally, the cost of using MSC-exosomes is much lower than that of MSCs.

6.2.2 MSC-exosome as a drug and miRNA delivery system for COVID-19

Designing miRNAs that specifically bind to the SARS-CoV-2 genome could allow disruption of SARSCoV-2 without any side effects on human gene expression [105]. Thus, MSC-exosomes that carry miRNAs may be a promising new approach to COVID-19 therapy. MSC- exosomes can be loaded with miRNAs either by direct insertion of the nucleic acids, or by collecting the exosomes from genetically-modified MSCs [106]. For example, miR-32, the first miRNA found to target viral RNA, binds to retrovirus PFV-1 transcripts to reduce viral replication [107], while miR-146a has been shown to specifically inhibit COX-2 in lung epithelial cells. miR-375 inhibits the trans-differentiation of myofibroblasts and their synthesis of collagen by blocking P38 [108].

MSC-exosomes are thus a novel intervention tool for COVID-19 treatment that can successfully deliver exogenous miRNAs to exert antiviral function. When combined with antiviral drugs such as Remdesivir, MSCexosomes can therefore serve as an effective drug delivery system [109].

\subsubsection{Potential of MSC-exosomes for vaccine development}

Spike protein is one of the structural proteins of SARS-CoV-2 that facilitates viral entry into the host cells. Therefore, spike protein is a good target for the development of anti-SARS coronavirus vaccines. Seraphin et al. showed that MSC-exosome-based vaccines containing the SARS-CoV-2 spike protein could induce high levels of neutralizing antibodies [17, 110-112].

\section{Clinical trials of MSCs and MSC-exosome therapy for COVID-19}

Current treatment trials for COVID-19 include corticosteroids, PD-1/PD-L1 checkpoint inhibitors, cytokine absorption devices, convalescent plasma [113] and anti-malarial and antiviral drugs [114]. Definite clinical benefits from these treatments have yet to be established and their safety and efficacy still need to be validated through Phase II and III clinical trials.

However, clinical trials have shown that MSC therapy and its derivatives are promising candidates for COVID-19 with known safety and efficacy. The United States FDA has approved MSCs for severe COVID-19 patients as compassionate use and progress has been made in this field. A study from Spain involving 13 COVID-19 patients requiring mechanical ventilation reported that no treatment-related adverse events (TRAEs) were observed [115]. After the first intervention with MSCs, clinical improvements were observed in 9 patients (70\%) after a median follow-up of 16 days. Seven patients were extubated and discharged, while 4 patients continued intubation (2 with improved ventilation and radiological parameters, and 2 with stable conditions). The research team compared the clinical progress and mortality rates of their study cohort with similar cases in the intensive care unit (ICU). The mortality rate of patients who received MSC therapy dropped from $70-85 \%$ to $15 \%$ (2/13). Only 2 patients died during the study, one from massive gastrointestinal bleeding unrelated to the MSC treatment, and the other from secondary 
Table 2. Completed clinical trials of MSCs and MSC-exosomes for the treatment of COVID-19.

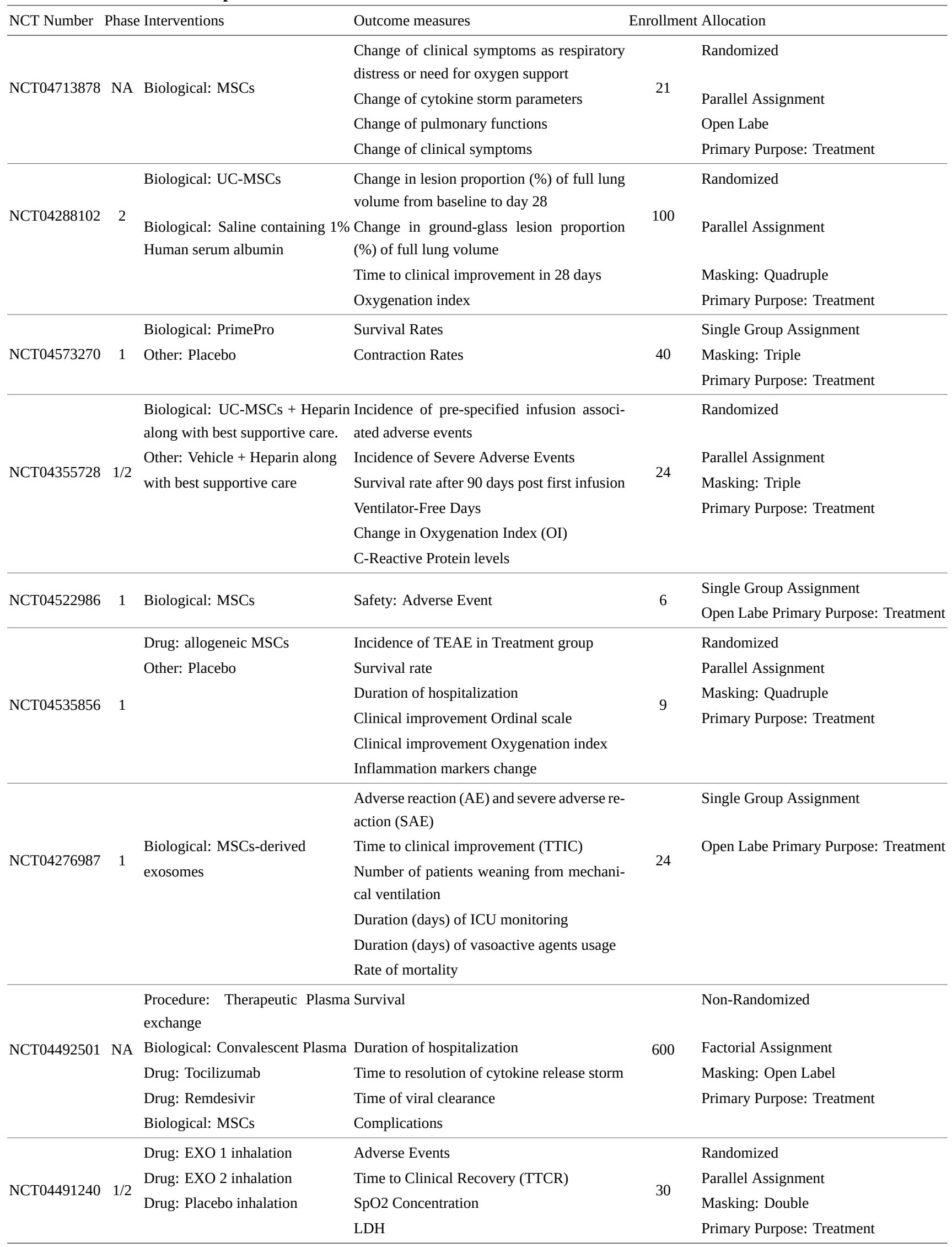

NA, Not Applicable. 
Table 3. Clinical trials of MSCs and MSC-exosomes for Covid-19 registered in Chictr.cn

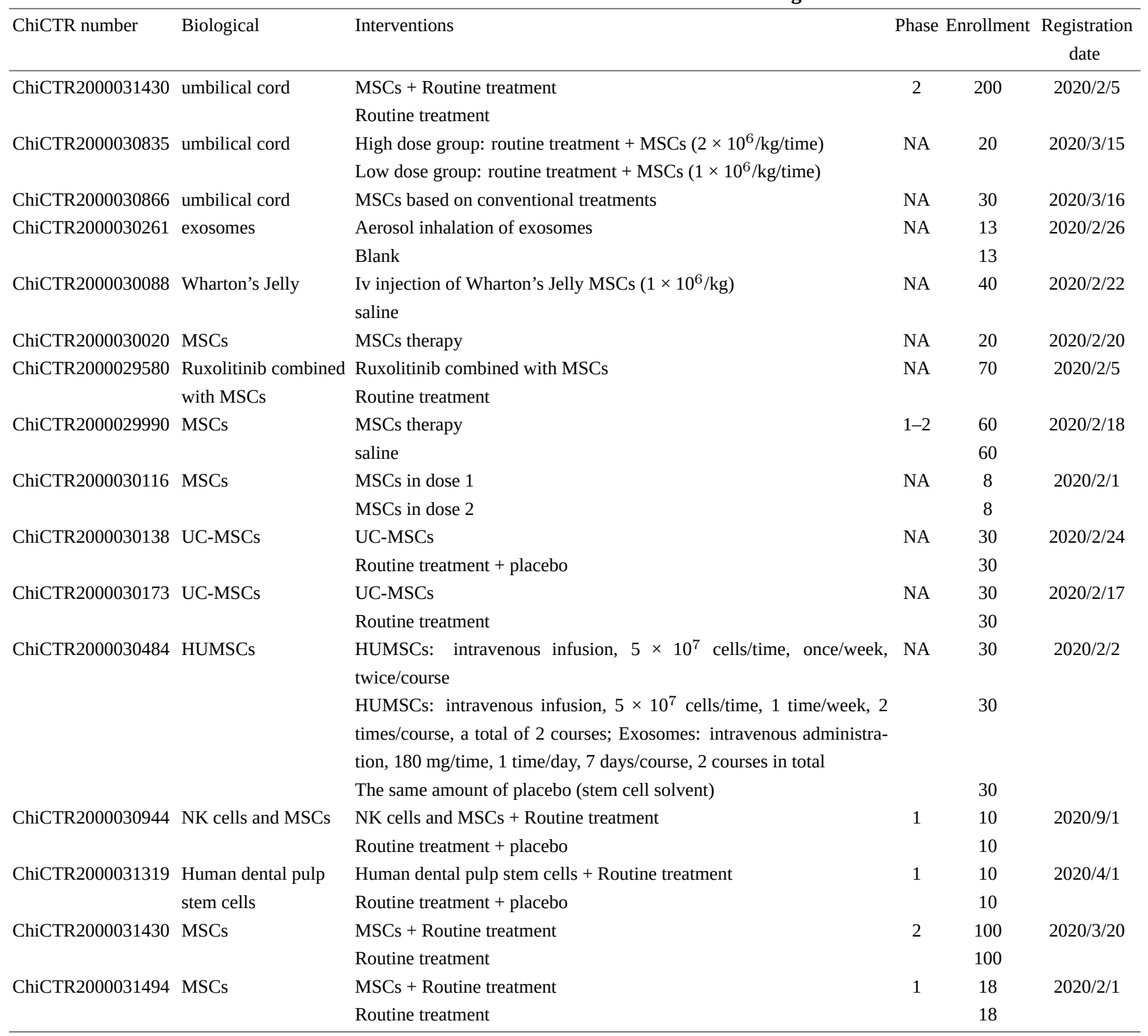

NA, Not Applicable.

fungal pneumonia caused by Candida spp. We searched for "COVID-19”, AND “exosome” OR "extracellular vesicles” OR “mesenchymal stem cells” up to April 22, 2021. Clinicaltrial.gov had 83 registered trials for the clinical use of MSCs, MSC-exosomes or MSC-exosome. Of these, 38 are ongoing and are recruiting patients. Nine trials had been completed to that date (Table 2). Using similar methodology, 16 registered clinical trials of MSCs for the treatment of COVID-19 were found in the Chinese Clinical Trial Register (Chictr).cn (Table 3). One clinical trial enrolled 101 patients with severe COVID-19 lung injury. Patients received human umbilical cord MSCs (HU-MSCs) $\left(4 \times 10^{7}\right.$ cells per infusion) on days 0,3 and 6 [116]. In this phase 1 trial (NCT 04252118), the researchers demonstrated that intravenous HU-MSCs are safe and well tolerated in patients with moderate and severe COVID-19. Compared to placebo, UC-MSCs reduced the volume of lung lesions (median difference: $-13.31 \%$, 95\% CI: $-29.14 \%, 2.13 \%, p$ $=0.080)$.

Compared with MSCs, MSC-exosomes have the ability to transmit and exchange intracellular chemical information. However, MSC-exosomes have received less attention than MSCs in COVID-19 research to date. At April 22, 2021, only two clinical trials using MSC-exosomes to treat COVID-19 had been completed (NCT04276987 and NCT04491240; see Table 2). Preliminary results of NCT04491240 released on 21 October 2020 showed that compared to placebo, the clinical recovery time, C-reaction protein (CRP) and layered double hydroxide (LDH) levels were lower for 10 consecutive days after inhalation of a solution containing $0.5-2 \times 10^{10}$ nanoparticles (MSCexosomes) twice daily. These effects may have been me- 
diated by the contents released from the MSC-exosomes, which included for example miRNA-126, miRNA-290, miRNA-21, miRNA-30b-3p, let-7, miRNA-200, miRNA145, miRNA-27a-3p, Syndecan-1, HGF and Ang-1 [117119]. Clearly, the application of MSC-exosomes instead of MSC therapy offers significant advantages [120], including more manageable dosing, easier storage, more readily available sources, better stability and lower immunogenicity [121-123]. Moreover, its noninvasive administration via inhalation avoids the side effects and pain that are commonly associated with parenteral therapy.

For these reasons, MSC-exosomes are a highly promising, cell-free therapy for COVID-19 [124, 125]. The U.S. Food and Drug Administration has in fact allowed the expanded use of MSC-exosome preparations for the treatment of COVID-19 [126]. These include aerosol inhalation of MSC-exosomes, targeted drug delivery based on MSCexosomes, and the development of MSC-exosome-based vaccines [127, 128]. However, a phase 3 trial is needed to further evaluate the effects of MSC-exosomes on mortality and long-term lung dysfunction from COVID-19.

\section{Conclusions}

COVID-19 treatment is currently very challenging, especially because of its complications and sequelae. Intravenous MSC administration or inhalation of MSCexosomes can improve the overall prognosis for COVID-19 by a variety of mechanisms: (1) through their immune regulation, (2) by promoting tissue repair and regeneration, (3) through their anti-fibrosis effect, and (4) by resuming normal vascular permeability. All these mechanisms can interact to strengthen lung repair and to protect the organs from damage caused by the excessive immune response. Despite the readily available sources, high proliferation rate, minimally invasive or noninvasive administration, and no ethical concerns, several challenges remain to be addressed with MSC and MSC-exosomes therapy. In particular, the dosing and timing of MSC and MSC-exosome therapy require careful consideration, since improper use may aggravate immunosuppression and lead to an unfavorable prognosis for COVID-19.

\section{Author contributions}

JM contributed to the conception of the study and led to the submission. XC performed the tables and wrote the manuscript; LL helped perform the figures with constructive discussions; MJ contributed significantly to manuscript preparation; All authors approved the final version.

\section{Ethics approval and consent to participate}

Not applicable.

\section{Acknowledgment}

Thanks to all the peer reviewers for their opinions and suggestions.

\section{Funding}

This work was supported by The National Natural Science Foundation of China (NSFC) [grant numbers 82070070].

\section{Conflict of interest}

The authors declare no conflict of interest.

\section{References}

[1] Yadav P, Vats R, Bano A, Bhardwaj R. Mesenchymal stem cell immunomodulation and regeneration therapeutics as an ameliorative approach for COVID-19 pandemics. Life Sciences. 2020; 263: 118588.

[2] Fang Y, Liu H, Huang H, Li H, Saqi A, Qiang L, et al. Distinct stem/progenitor cells proliferate to regenerate the trachea, intrapulmonary airways and alveoli in COVID-19 patients. Cell Research. 2020; 30: 705-707.

[3] Hernandez JJ, Beaty DE, Fruhwirth LL, Lopes Chaves AP, Riordan NH. Dodging COVID-19 infection: low expression and localization of ACE2 and TMPRSS2 in multiple donor-derived lines of human umbilical cord-derived mesenchymal stem cells. Journal of Translational Medicine. 2021; 19: 149.

[4] Liu S, Peng D, Qiu H, Yang K, Fu Z, Zou L. Mesenchymal stem cells as a potential therapy for COVID-19. Stem Cell Research \& Therapy. 2020; 11: 169.

[5] Manolio TA, Boerwinkle E, O’Donnell CJ, Wilson AF. Genetics of Ultrasonographic Carotid Atherosclerosis. Arteriosclerosis, Thrombosis, and Vascular Biology. 2004; 24: 1567-1577.

[6] Khoury M, Cuenca J, Cruz FF, Figueroa FE, Rocco PRM, Weiss DJ. Current status of cell-based therapies for respiratory virus infections: applicability to COVID-19. European Respiratory Journal. 2020; 55: 2000858.

[7] Teo SP. Review of COVID-19 mRNA Vaccines: BNT162b2 and mRNA-1273. Journal of Pharmacy Practice. 2021. (in press)

[8] Wang X, Xu W, Hu G, Xia S, Sun Z, Liu Z, et al. Retraction Note to: SARS-CoV-2 infects T lymphocytes through its spike protein-mediated membrane fusion. Cellular \& Molecular Immunology. 2020; 17: 894-894.

[9] Zhang J, Xie B, Hashimoto K. Current status of potential therapeutic candidates for the COVID-19 crisis. Brain, Behavior, and Immunity. 2020; 87: 59-73.

[10] Abraham A, Krasnodembskaya A. Mesenchymal stem cellderived extracellular vesicles for the treatment of acute respiratory distress syndrome. Stem Cells Translational Medicine. 2020; 9: 28-38.

[11] Zhang L, Hei F. Mesenchymal Stem Cell-derived Exosomes: are they another Therapeutic Method for Extracorporeal Membrane Oxygenation-supported Acute Respiratory Distress Syndrome? American Journal of Respiratory and Critical Care Medicine. 2020; 202: 1602-1603. 
[12] Li Z, Niu S, Guo B, Gao T, Wang L, Wang Y, et al. Stem cell therapy for COVID-19, ARDS and pulmonary fibrosis. Cell Proliferation. 2020; 53: e12939.

[13] Ji H, Liu C, Zhao R. Stem cell therapy for COVID-19 and other respiratory diseases: Global trends of clinical trials. World Journal of Stem Cells. 2020; 12: 471-480.

[14] Wang J, Zou W, Liu J. Mesenchymal stem cells in the treatment of COVID-19-progress and challenges. Chinese Journal of Biotechnology. 2020; 36: 1970-1978.

[15] Aheget H, Tristán-Manzano M, Mazini L, Cortijo-Gutierrez M, Galindo-Moreno P, Herrera C, et al. Exosome: A New Player in Translational Nanomedicine. Journal of Clinical Medicine. 2020; 9: 2380.

[16] Muthu S, Bapat A, Jain R, Jeyaraman N, Jeyaraman M. Exosomal therapy-a new frontier in regenerative medicine. Stem cell Investigation. 2021; 8: 7.

[17] Hassanpour M, Rezaie J, Nouri M, Panahi Y. The role of extracellular vesicles in COVID-19 virus infection. Infection, Genetics and Evolution. 2020; 85: 104422.

[18] Sengupta V, Sengupta S, Lazo A, Woods P, Nolan A, Bremer N. Exosomes Derived from Bone Marrow Mesenchymal Stem Cells as Treatment for Severe COVID-19. Stem Cells and Development. 2020; 29: 747-754.

[19] Akbari A, Rezaie J. Potential therapeutic application of mesenchymal stem cell-derived exosomes in SARS-CoV-2 pneumonia. Stem Cell Research \& Therapy. 2020; 11: 356.

[20] Alzahrani FA, Saadeldin IM, Ahmad A, Kumar D, Azhar EI, Siddiqui AJ, et al. The Potential Use of Mesenchymal Stem Cells and their Derived Exosomes as Immunomodulatory Agents for COVID-19 Patients. Stem Cells International. 2020; 2020: 8835986.

[21] Raghav A, Khan ZA, Upadhayay VK, Tripathi P, Gautam KA, Mishra BK, et al. Mesenchymal Stem Cell-Derived Exosomes Exhibit Promising Potential for Treating SARS-CoV-2-Infected Patients. Cells. 2021; 10: 587.

[22] Chouw A, Milanda T, Sartika CR, Kirana MN, Halim D, Faried A. Potency of Mesenchymal Stem Cell and Its Secretome in Treating COVID-19. Regenerative Engineering and Translational Medicine. 2021. (in press)

[23] Xiao K, He W, Guan W, Hou F, Yan P, Xu J, et al. Mesenchymal stem cells reverse EMT process through blocking the activation of NF-KB and Hedgehog pathways in LPS-induced acute lung injury. Cell Death \& Disease. 2020; 11: 863.

[24] Aliotta JM, Pereira M, Wen S, Dooner MS, Del Tatto M, Papa E, et al. Exosomes induce and reverse monocrotaline-induced pulmonary hypertension in mice. Cardiovascular Research. 2016; 110: 319-330.

[25] Qiao Q, Liu X, Yang T, Cui K, Kong L, Yang C, et al. Nanomedicine for acute respiratory distress syndrome: the latest application, targeting strategy, and rational design. Acta Pharmaceutica Sinica B. 2021. (in press)

[26] Khatri M, Richardson LA, Meulia T. Mesenchymal stem cellderived extracellular vesicles attenuate influenza virus-induced acute lung injury in a pig model. Stem Cell Research \& Therapy. 2018; 9: 17.

[27] Fang S, Zhang H, Wang C, He B, Liu X, Meng X, et al. Small extracellular vesicles derived from human mesenchymal stromal cells prevent group 2 innate lymphoid cell-dominant allergic airway inflammation through delivery of miR-146a-5p. Journal of Extracellular Vesicles. 2020; 9: 1723260.

[28] Xiao C, Wang K, Xu Y, Hu H, Zhang N, Wang Y, et al. Transplanted Mesenchymal Stem Cells Reduce Autophagic Flux in Infarcted Hearts via the Exosomal Transfer of miR-125b. Circulation Research. 2018; 123: 564-578.

[29] Bruno S, Grange C, Collino F, Deregibus MC, Cantaluppi V, Biancone L, et al. Microvesicles derived from mesenchymal stem cells enhance survival in a lethal model of acute kidney injury. PLoS ONE. 2012; 7: e33115.

[30] Li T, Yan Y, Wang B, Qian H, Zhang X, Shen L, et al. Exosomes
Derived from Human Umbilical Cord Mesenchymal Stem Cells Alleviate Liver Fibrosis. Stem Cells and Development. 2013; 22: 845-854.

[31] Lou G, Yang Y, Liu F, Ye B, Chen Z, Zheng M, et al. MiR-122 modification enhances the therapeutic efficacy of adipose tissuederived mesenchymal stem cells against liver fibrosis. Journal of Cellular and Molecular Medicine. 2017; 21: 2963-2973.

[32] Hogan BLM, Barkauskas CE, Chapman HA, Epstein JA, Jain R, Hsia CCW, et al. Repair and regeneration of the respiratory system: complexity, plasticity, and mechanisms of lung stem cell function. Cell Stem Cell. 2014; 15: 123-138.

[33] Chamberlain CS, Clements AEB, Kink JA, Choi U, Baer GS, Halanski MA, et al. Extracellular Vesicle-Educated Macrophages Promote Early Achilles Tendon Healing. Stem Cells. 2019; 37: 652-662.

[34] Heidari N, Abbasi-Kenarsari H, Namaki S, Baghaei K, Zali MR, Ghaffari Khaligh S, et al. Adipose-derived mesenchymal stem cell-secreted exosome alleviates dextran sulfate sodium-induced acute colitis by Treg cell induction and inflammatory cytokine reduction. Journal of Cellular Physiology. 2021; 236: 5906 5920.

[35] Shahir M, Mahmoud Hashemi S, Asadirad A, Varahram M, Kazempour-Dizaji M, Folkerts G, et al. Effect of mesenchymal stem cell-derived exosomes on the induction of mouse tolerogenic dendritic cells. Journal of Cellular Physiology. 2020; 235: 7043-7055.

[36] Liu L, Jin X, Hu C, Li R, Zhou Z, Shen C. Exosomes Derived from Mesenchymal Stem Cells Rescue Myocardial Ischaemia/Reperfusion Injury by Inducing Cardiomyocyte Autophagy via AMPK and Akt Pathways. Cellular Physiology and Biochemistry. 2017; 43: 52-68.

[37] Jayaramayya K, Mahalaxmi I, Subramaniam MD, Raj N, Dayem AA, Lim KM, et al. Immunomodulatory effect of mesenchymal stem cells and mesenchymal stem-cell-derived exosomes for COVID-19 treatment. BMB Reports. 2020; 53: 400-412.

[38] Lu Z, Chang W, Meng S, Xu X, Xie J, Guo F, et al. Mesenchymal stem cells induce dendritic cell immune tolerance via paracrine hepatocyte growth factor to alleviate acute lung injury. Stem Cell Research \& Therapy. 2019; 10: 372.

[39] Reis M, Mavin E, Nicholson L, Green K, Dickinson AM, Wang X. Mesenchymal Stromal Cell-Derived Extracellular Vesicles Attenuate Dendritic Cell Maturation and Function. Frontiers in Immunology. 2018; 9: 2538.

[40] Leng Z, Zhu R, Hou W, Feng Y, Yang Y, Han Q, et al. Transplantation of ACE2(-) Mesenchymal Stem Cells Improves the Outcome of Patients with COVID-19 Pneumonia. Aging and Disease. 2020; 11: 216.

[41] Luz-Crawford P, Kurte M, Bravo-Alegría J, Contreras R, NovaLamperti E, Tejedor G, et al. Mesenchymal stem cells generate a CD4+CD25+Foxp3+ regulatory $\mathrm{T}$ cell population during the differentiation process of Th1 and Th17 cells. Stem Cell Research \& Therapy. 2013; 4: 65.

[42] Liao M, Liu Y, Yuan J, Wen Y, Xu G, Zhao J, et al. Singlecell landscape of bronchoalveolar immune cells in patients with COVID-19. Nature Medicine. 2020; 26: 842-844.

[43] Zhang X, Tan Y, Ling Y, Lu G, Liu F, Yi Z, et al. Viral and host factors related to the clinical outcome of COVID-19. Nature. 2020; 583: 437-440.

[44] Brody AR, Salazar KD, Lankford SM. Mesenchymal stem cells modulate lung injury. Proceedings of the American Thoracic Society. 2010; 7: 130-133.

[45] Chen X, Wu S, Tang L, Ma L, Wang F, Feng H, et al. Mesenchymal stem cells overexpressing heme oxygenase-1 ameliorate lipopolysaccharide-induced acute lung injury in rats. Journal of Cellular Physiology. 2019; 234: 7301-7319.

[46] Li X, Michaeloudes C, Zhang Y, Wiegman CH, Adcock IM, Lian Q, et al. Mesenchymal stem cells alleviate oxidative stressinduced mitochondrial dysfunction in the airways. Journal of Allergy and Clinical Immunology. 2018; 141: 1634-1645.e5. 
[47] Gao F, Chiu SM, Motan DAL, Zhang Z, Chen L, Ji H, et al. Mesenchymal stem cells and immunomodulation: current status and future prospects. Cell Death \& Disease. 2016; 7: e2062.

[48] Bernardo ME, Fibbe WE. Mesenchymal stromal cells: sensors and switchers of inflammation. Cell Stem Cell. 2013; 13: 392402.

[49] Prockop DJ. Concise review: two negative feedback loops place mesenchymal stem/stromal cells at the center of early regulators of inflammation. Stem Cells. 2013; 31: 2042-2046.

[50] Matthay MA. Therapeutic potential of mesenchymal stromal cells for acute respiratory distress syndrome. Annals of the American Thoracic Society. 2015; 12: S54-S57.

[51] Matthay MA, Goolaerts A, Howard JP, Lee JW. Mesenchymal stem cells for acute lung injury: preclinical evidence. Critical Care Medicine. 2010; 38: S569-S573.

[52] Taghavi-Farahabadi M, Mahmoudi M, Soudi S, Hashemi SM. Hypothesis for the management and treatment of the COVID19-induced acute respiratory distress syndrome and lung injury using mesenchymal stem cell-derived exosomes. Medical Hypotheses. 2020; 144: 109865.

[53] Tsuchiya A, Takeuchi S, Iwasawa T, Kumagai M, Sato T, Motegi S, et al. Therapeutic potential of mesenchymal stem cells and their exosomes in severe novel coronavirus disease 2019 (COVID-19) cases. Inflammation and Regeneration. 2020; 40: 14.

[54] Liu J, Li S, Liu J, Liang B, Wang X, Wang H, et al. Longitudinal characteristics of lymphocyte responses and cytokine profiles in the peripheral blood of SARS-CoV-2 infected patients. EBioMedicine. 2020; 55: 102763.

[55] Coelho A, Alvites RD, Branquinho MV, Guerreiro SG, Maurício AC. Mesenchymal Stem Cells (MSCs) as a Potential Therapeutic Strategy in COVID-19 Patients: Literature Research. Frontiers in Cell and Developmental Biology. 2020; 8: 602647.

[56] Song N, Wakimoto H, Rossignoli F, Bhere D, Ciccocioppo R, Chen KS, et al. Mesenchymal stem cell immunomodulation: In pursuit of controlling COVID-19 related cytokine storm. Stem Cells. 2021; 39: 707-722.

[57] Wang W, Lei W, Jiang L, Gao S, Hu S, Zhao Z, et al. Therapeutic mechanisms of mesenchymal stem cells in acute respiratory distress syndrome reveal potentials for Covid-19 treatment. Journal of Translational Medicine. 2021; 19: 198.

[58] Mahat RK, Panda S, Rathore V, Swain S, Yadav L, Sah SP. The dynamics of inflammatory markers in coronavirus disease-2019 (COVID-19) patients: a systematic review and meta-analysis. Clinical Epidemiology and Global Health. 2021; 11: 100727.

[59] Li D, Wang C, Chi C, Wang Y, Zhao J, Fang J, et al. Bone Marrow Mesenchymal Stem Cells Inhibit LipopolysaccharideInduced Inflammatory Reactions in Macrophages and Endothelial Cells. Mediators of Inflammation. 2016; 2016: 2631439.

[60] Basiri A, Pazhouhnia Z, Beheshtizadeh N, Hoseinpour M, Saghazadeh A, Rezaei N. Regenerative Medicine in COVID-19 Treatment: Real Opportunities and Range of Promises. Stem Cell Reviews and Reports. 2021; 17: 163-175.

[61] Sang L, Guo X, Shi J, Hou S, Fan H, Lv Q. Characteristics and Developments in Mesenchymal Stem Cell Therapy for COVID19: an Update. Stem Cells International. 2021; 2021: 1-16.

[62] Grégoire C, Lechanteur C, Briquet A, Baudoux É, Baron F, Louis E, et al. Review article: mesenchymal stromal cell therapy for inflammatory bowel diseases. Alimentary Pharmacology \& Therapeutics. 2017; 45: 205-221.

[63] Mangalmurti N, Hunter CA. Cytokine Storms: Understanding COVID-19. Immunity. 2020; 53: 19-25.

[64] Meng F, Xu R, Wang S, Xu Z, Zhang C, Li Y, et al. Human umbilical cord-derived mesenchymal stem cell therapy in patients with COVID-19: a phase 1 clinical trial. Signal Transduction and Targeted Therapy. 2020; 5: 172.

[65] Elrashdy F, Aljaddawi AA, Redwan EM, Uversky VN. On the potential role of exosomes in the COVID-19 reinfec- tion/reactivation opportunity. Journal of Biomolecular Structure and Dynamics. 2021; 39: 5831-5842.

[66] Basil MC, Katzen J, Engler AE, Guo M, Herriges MJ, Kathiriya $\mathrm{JJ}$, et al. The Cellular and Physiological Basis for Lung Repair and Regeneration: Past, Present, and Future. Cell Stem Cell. 2020; 26: 482-502.

[67] Jerkic M, Masterson C, Ormesher L, Gagnon S, Goyal S, Rabani $\mathrm{R}$, et al. Overexpression of IL-10 Enhances the Efficacy of Human Umbilical-Cord-Derived Mesenchymal Stromal Cells in E. coli Pneumosepsis. Journal of Clinical Medicine. 2019; 8: 847.

[68] Xiong J, Chen L, Zhang L, Bao L, Shi Y. Mesenchymal Stromal Cell-Based Therapy: a Promising Approach for Severe COVID19. Cell Transplantation. 2021; 30: 096368972199545.

[69] Song J, Zhang C, Fan X, Meng F, Xu Z, Xia P, et al. Immunological and inflammatory profiles in mild and severe cases of COVID-19. Nature Communications. 2020; 11: 3410.

[70] Xu Z, Shi L, Wang Y, Zhang J, Huang L, Zhang C, et al. Pathological findings of COVID-19 associated with acute respiratory distress syndrome. The Lancet Respiratory Medicine. 2020; 8: 420-422.

[71] Szekely L, Bozoky B, Bendek M, Ostad M, Lavignasse P, Haag $\mathrm{L}$, et al. Pulmonary stromal expansion and intra-alveolar coagulation are primary causes of COVID-19 death. Heliyon. 2021; 7: e07134.

[72] Bernheim A, Mei X, Huang M, Yang Y, Fayad ZA, Zhang N, et al. Chest CT Findings in Coronavirus Disease-19 (COVID19): Relationship to Duration of Infection. Radiology. 2020; 295: 200463.

[73] Giamarellos-Bourboulis EJ, Netea MG, Rovina N, Akinosoglou $\mathrm{K}$, Antoniadou A, Antonakos N, et al. Complex Immune Dysregulation in COVID-19 Patients with Severe Respiratory Failure. Cell Host \& Microbe. 2020; 27: 992-1000.e3.

[74] Dutra Silva J, Su Y, Calfee CS, Delucchi KL, Weiss D, McAuley $\mathrm{DF}$, et al. Mesenchymal stromal cell extracellular vesicles rescue mitochondrial dysfunction and improve barrier integrity in clinically relevant models of ARDS. European Respiratory Journal. 2021; 58: 2002978.

[75] Silva JD, Krasnodembskaya AD. Investigation of the MSC Paracrine Effects on Alveolar-Capillary Barrier Integrity in the in Vitro Models of ARDS. Methods in Molecular Biology. 2021; 97: 63-81.

[76] Ragni E, Banfi F, Barilani M, Cherubini A, Parazzi V, Larghi $\mathrm{P}$, et al. Extracellular Vesicle-Shuttled mRNA in Mesenchymal Stem Cell Communication. Stem Cells. 2017; 35: 1093-1105.

[77] Muraca M, Pessina A, Pozzobon M, Dominici M, Galderisi U, Lazzari L, et al. Mesenchymal stromal cells and their secreted extracellular vesicles as therapeutic tools for COVID-19 pneumonia? Journal of Controlled Release. 2020; 325: 135-140.

[78] Harrell CR, Jovicic N, Djonov V, Arsenijevic N, Volarevic V. Mesenchymal Stem Cell-Derived Exosomes and Other Extracellular Vesicles as New Remedies in the Therapy of Inflammatory Diseases. Cells. 2019; 8: 1605.

[79] Zhu Y, Feng X, Abbott J, Fang X, Hao Q, Monsel A, et al. Human mesenchymal stem cell microvesicles for treatment of Escherichia coli endotoxin-induced acute lung injury in mice. Stem Cells. 2014; 32: 116-125.

[80] Gorman E, Millar J, McAuley D, O’Kane C. Mesenchymal stromal cells for acute respiratory distress syndrome (ARDS), sepsis, and COVID-19 infection: optimizing the therapeutic potential. Expert Review of Respiratory Medicine. 2021; 15: 301324.

[81] Mei SHJ, McCarter SD, Deng Y, Parker CH, Liles WC, Stewart DJ. Prevention of LPS-induced acute lung injury in mice by mesenchymal stem cells overexpressing angiopoietin 1 . PLoS Medicine. 2007; 4: e269.

[82] Xu J, Qu J, Cao L, Sai Y, Chen C, He L, et al. Mesenchymal stem cell-based angiopoietin-1 gene therapy for acute lung injury induced by lipopolysaccharide in mice. The Journal of Pathology. 2008; 214: 472-481. 
[83] Magro C, Mulvey JJ, Berlin D, Nuovo G, Salvatore S, Harp J, et al. Complement associated microvascular injury and thrombosis in the pathogenesis of severe COVID-19 infection: a report of five cases. Translational Research. 2020; 220: 1-13.

[84] Sinclair K, Yerkovich ST, Chambers DC. Mesenchymal stem cells and the lung. Respirology. 2013; 18: 397-411.

[85] Sinclair KA, Yerkovich ST, Chen T, McQualter JL, Hopkins PM, Wells CA, et al. Mesenchymal Stromal Cells are Readily Recoverable from Lung Tissue, but not the Alveolar Space, in Healthy Humans. Stem Cells. 2016; 34: 2548-2558.

[86] De Biasi S, Meschiari M, Gibellini L, Bellinazzi C, Borella R, Fidanza L, et al. Marked T cell activation, senescence, exhaustion and skewing towards TH17 in patients with COVID-19 pneumonia. Nature Communications. 2020; 11: 3434.

[87] Du H, Jiang L, Geng W, Li J, Zhang R, Dang J, et al. Growth Factor-Reinforced ECM Fabricated from Chemically Hypoxic MSC Sheet with Improved in Vivo Wound Repair Activity. BioMed Research International. 2017; 2017: 2578017.

[88] Rocha JLM, de Oliveira WCF, Noronha NC, dos Santos NCD, Covas DT, Picanço-Castro V, et al. Mesenchymal Stromal Cells in Viral Infections: Implications for COVID-19. Stem Cell Reviews and Reports. 2021; 17: 71-93.

[89] Shukla L, Yuan Y, Shayan R, Greening DW, Karnezis T. Fat Therapeutics: The Clinical Capacity of Adipose-Derived Stem Cells and Exosomes for Human Disease and Tissue Regeneration. Frontiers in Pharmacology. 2020; 11: 158.

[90] Wu J, Song D, Li Z, Guo B, Xiao Y, Liu W, et al. Immunity-andmatrix-regulatory cells derived from human embryonic stem cells safely and effectively treat mouse lung injury and fibrosis. Cell Research. 2020; 30: 794-809.

[91] Paliwal S, Chaudhuri R, Agrawal A, Mohanty S. Regenerative abilities of mesenchymal stem cells through mitochondrial transfer. Journal of Biomedical Science. 2018; 25: 31.

[92] Qin H, Zhao A. Mesenchymal stem cell therapy for acute respiratory distress syndrome: from basic to clinics. Protein \& Cell. 2020; 11: 707-722.

[93] Varderidou-Minasian S, Lorenowicz MJ. Mesenchymal stro$\mathrm{mal} / \mathrm{stem}$ cell-derived extracellular vesicles in tissue repair: challenges and opportunities. Theranostics. 2020; 10: 5979_ 5997.

[94] Al-Khawaga S, Abdelalim EM. Potential application of mesenchymal stem cells and their exosomes in lung injury: an emerging therapeutic option for COVID-19 patients. Stem Cell Research \& Therapy. 2020; 11: 437.

[95] Allan D, Tieu A, Lalu M, Burger D. Mesenchymal stromal cellderived extracellular vesicles for regenerative therapy and immune modulation: Progress and challenges toward clinical application. STEM CELLS Translational Medicine. 2020; 9: 3946.

[96] Basiri A, Mansouri F, Azari A, Ranjbarvan P, Zarein F, Heidari A, et al. Stem Cell Therapy Potency in Personalizing Severe COVID-19 Treatment. Stem Cell Reviews and Reports. 2021; 17: 193-213.

[97] Wang J, Huang R, Xu Q, Zheng G, Qiu G, Ge M, et al. Mesenchymal Stem Cell-Derived Extracellular Vesicles Alleviate Acute Lung Injury Via Transfer of miR-27a-3p. Critical Care Medicine. 2020; 48: e599-e610.

[98] Lucas C, Wong P, Klein J, Castro TBR, Silva J, Sundaram M, et al. Longitudinal analyses reveal immunological misfiring in severe COVID-19. Nature. 2020; 584: 463-469.

[99] Moll G, Drzeniek N, Kamhieh-Milz J, Geissler S, Volk HD, Reinke P. MSC Therapies for COVID-19: Importance of Patient Coagulopathy, Thromboprophylaxis, Cell Product Quality and Mode of Delivery for Treatment Safety and Efficacy. Frontiers in Immunology. 2020; 11: 1091.

[100] Riphagen S, Gomez X, Gonzalez-Martinez C, Wilkinson N, Theocharis P. Hyperinflammatory shock in children during COVID-19 pandemic. The Lancet. 2020; 395: 1607-1608.

[101] Askenase PW. COVID-19 therapy with mesenchymal stromal cells (MSC) and convalescent plasma must consider exosome involvement: do the exosomes in convalescent plasma antagonize the weak immune antibodies? Journal of Extracellular Vesicles. 2020; 10: e12004

[102] Cai Y, Li J, Jia C, He Y, Deng C. Therapeutic applications of adipose cell-free derivatives: a review. Stem Cell Research \& Therapy. 2020; 11: 312.

[103] Xiao K, Hou F, Huang X, Li B, Qian ZR, Xie L. Mesenchymal stem cells: current clinical progress in ARDS and COVID-19. Stem Cell Research \& Therapy. 2020; 11: 305.

[104] Harrell CR, Jovicic BP, Djonov V, Volarevic V. Therapeutic Potential of Mesenchymal Stem Cells and their Secretome in the Treatment of SARS-CoV-2-Induced Acute Respiratory Distress Syndrome. Analytical Cellular Pathology. 2020; 2020: 1939768.

[105] Ivashchenko AA, Dmitriev KA, Vostokova NV, Azarova VN, Blinow AA, Egorova AN, et al. AVIFAVIR for Treatment of Patients with Moderate COVID-19: Interim Results of a Phase II/III Multicenter Randomized Clinical Trial. Clinical Infectious Diseases. 2021; 73: 531-534.

[106] Jamalkhah M, Asaadi Y, Azangou-Khyavy M, Khanali J, Soleimani M, Kiani J, et al. MSC-derived exosomes carrying a cocktail of exogenous interfering RNAs an unprecedented therapy in era of COVID-19 outbreak. Journal of Translational Medicine. 2021; 19: 164.

[107] Elahi FM, Farwell DG, Nolta JA, Anderson JD. Preclinical translation of exosomes derived from mesenchymal stem/stromal cells. Stem Cells. 2020; 38: 15-21.

[108] de Jong B, Barros ER, Hoenderop JGJ, Rigalli JP. Recent Advances in Extracellular Vesicles as Drug Delivery Systems and Their Potential in Precision Medicine. Pharmaceutics. 2020; 12: 1006.

[109] O’Driscoll L. Extracellular vesicles from mesenchymal stem cells as a Covid-19 treatment. Drug Discovery Today. 2020; 25: 1124-1125.

[110] Kuate S, Cinatl J, Doerr HW, Uberla K. Exosomal vaccines containing the $\mathrm{S}$ protein of the SARS coronavirus induce high levels of neutralizing antibodies. Virology. 2007;362(1):26-37.

[111] Jafari D, Shajari S, Jafari R, Mardi N, Gomari H, Ganji F, et al. Designer Exosomes: a New Platform for Biotechnology Therapeutics. BioDrugs. 2020; 34: 567-586.

[112] Rezakhani L, Kelishadrokhi AF, Soleimanizadeh A, Rahmati S. Mesenchymal stem cell (MSC)-derived exosomes as a cellfree therapy for patients Infected with COVID-19: Real opportunities and range of promises. Chemistry and Physics of Lipids. 2021; 234: 105009.

[113] Yoon HA, Bartash R, Gendlina I, Rivera J, Nakouzi A, Bortz $\mathrm{RH}, 3 \mathrm{rd}$, et al. Treatment of severe COVID-19 with convalescent plasma in Bronx, NYC. JCI insight. 2021. (in press)

[114] Beigel JH, Tomashek KM, Dodd LE, Mehta AK, Zingman BS, Kalil AC, et al. Remdesivir for the Treatment of Covid-19 - Final Report. New England Journal of Medicine. 2020; 383: 18131826.

[115] Sánchez-Guijo F, García-Arranz M, López-Parra M, Monedero P, Mata-Martínez C, Santos A, et al. Adipose-derived mesenchymal stromal cells for the treatment of patients with severe SARS-CoV-2 pneumonia requiring mechanical ventilation. a proof of concept study. EClinicalMedicine. 2020; 25: 100454.

[116] Shi L, Huang H, Lu X, Yan X, Jiang X, Xu R, et al. Effect of human umbilical cord-derived mesenchymal stem cells on lung damage in severe COVID-19 patients: a randomized, doubleblind, placebo-controlled phase 2 trial. Signal Transduction and Targeted Therapy. 2021; 6: 58.

[117] Xu N, He D, Shao Y, Qu Y, Ye K, Memet O, et al. Lung-derived exosomes in phosgene-induced acute lung injury regulate the functions of mesenchymal stem cells partially via miR-28-5p. Biomedicine \& Pharmacotherapy. 2020; 121: 109603.

[118] Gardin C, Ferroni L, Chachques JC, Zavan B. Could Mesenchymal Stem Cell-Derived Exosomes Be a Therapeutic Op- 
tion for Critically Ill COVID-19 Patients? Journal of Clinical Medicine. 2020; 9: 2762.

[119] Khalaj K, Figueira RL, Antounians L, Lauriti G, Zani A. Systematic review of extracellular vesicle-based treatments for lung injury: are EVs a potential therapy for COVID-19? Journal of Extracellular Vesicles. 2020; 9: 1795365.

[120] Kim JY, Rhim W, Yoo Y, Kim D, Ko K, Heo Y, et al. Defined MSC exosome with high yield and purity to improve regenerative activity. Journal of Tissue Engineering. 2021; 12: 204173142110086.

[121] Gore AV, Bible LE, Livingston DH, Mohr AM, Sifri ZC. Mesenchymal stem cells enhance lung recovery after injury, shock, and chronic stress. Surgery. 2016; 159: 1430-1435.

[122] Harrell CR, Sadikot R, Pascual J, Fellabaum C, Jankovic MG, Jovicic N, et al. Mesenchymal Stem Cell-Based Therapy of Inflammatory Lung Diseases: Current Understanding and Future Perspectives. Stem Cells International. 2019; 2019: 4236973.

[123] Mohammadipoor A, Antebi B, Batchinsky AI, Cancio LC. Therapeutic potential of products derived from mesenchymal stem/stromal cells in pulmonary disease. Respiratory Research. 2018; 19: 218.

[124] Gupta A, Kashte S, Gupta M, Rodriguez HC, Gautam SS, Kadam S. Mesenchymal stem cells and exosome therapy for COVID-19: current status and future perspective. Human Cell. 2020; 33: 907-918.

[125] Bari E, Ferrarotti I, Saracino L, Perteghella S, Torre ML, Corsico AG. Mesenchymal Stromal Cell Secretome for Severe COVID-19 Infections: Premises for the Therapeutic Use. Cells. 2020; 9: 924

[126] Chang Y, Lo H, Cheng S, Chang K, Lin X, Lee S, et al. Therapeutic effects of a single injection of human umbilical mesenchymal stem cells on acute and chronic colitis in mice. Scientific Reports. 2019; 9: 5832.

[127] Gentile P, Sterodimas A, Pizzicannella J, Calabrese C, Garcovich S. Research progress on Mesenchymal Stem Cells (MSCs), Adipose-Derived Mesenchymal Stem Cells (ADMSCs), Drugs, and Vaccines in Inhibiting COVID-19 Disease. Aging and Disease. 2020; 11: 1191.

[128] Pinky, Gupta S, Krishnakumar V, Sharma Y, Dinda AK, Mohanty S. Mesenchymal Stem Cell Derived Exosomes: a Nano Platform for Therapeutics and Drug Delivery in Combating COVID-19. Stem Cell Reviews and Reports. 2021; 17: 33-43.

Abbreviations: ACE2, angiotensin-converting enzyme 2; ADAMTS2, ADAM Metallopeptidase With Thrombospondin Type 1 Motif 2; Ang-2, Angiopoietin-2; APCs, Antigen presenting cells; ARDS, acute respiratory distress syndrome; AZD1222, Oxford-AstraZeneca 1,2's Cha- dox1 nCoV-19; bFGF, basic fibroblast growth factor; COL15A1, Collagen 15A1; COL-I, collagen-1; COVID19, Corona Virus Disease 2019; COX-2, cyclooxygenase2; CRS, cytokine release syndrome; CRP, C-reaction protein; CXCL10, C-X-C Motif Chemokine Ligand 10; DC, Dendritic cells; ECM, extracelluar matrix; FDA, Food and Drug Administration; G-CSF, granulocyte colony stimulating factor; hESCs, Human embryonic stem cells; HGF, human growth factor; HMGB1, High mobility group box chromosomal protein 1; HLA, human leukocyte antigen; HO-1, heme oxygenase-1; HTRA1, high temperature requirement A1; HU-MSCs, human umbilical cord mesenchymal stem cells; ICU, intensive care unit; IDO, indoleamine 2,3-dioxygenase; IFN, interferon; IgM, immunoglobin M; IL, interleukin; IMRCs, immune and stromal regulatory cells; IP-10, interferon gamma induced protein-10; KGF, keratinocyte growth factor; LOX, lipoxygenase; LDH, layered double hydroxide; MCP-1/CCL2, Monocyte chemoattractant protein-1; MHC-1, major histocompatibility complex 1; MIP-1, Macrophage inflammatory protein-1; MMPs, matrix metalloproteinases; mRNA, messenger RNA; MSCs, Mesenchymal stem cells; MSCEVs, MSC-derived extracellular vesicles; NLRP3, NODlike receptor protein 3; PGE2, prostaglandin E2; PIK3R2, phosphoinositide-3-kinase regulatory subunit 2; SARSCOV-2, severe respiratory syndrome coronavirus 2; SOD, superoxide dismutase; TGF- $\beta$, transforming growth factor$\beta$; TNF- $\alpha$, tumor necrosis factor- $\alpha$; Th, T helper type; TIMP2, tissue inhibitor of metalloproteinases 2; TRH6, thyrotropin-releasing hormone-6; TRAEs, Treatmentrelated adverse events; VEGF, Vascular endothelial growth factor.

Keywords: COVID-19; SARS-CoV-2; Mesenchymal stem cell; Exosome; Immunoregulation

Send correspondence to: Jie Meng, Department of Pulmonary and Critical Care Medicine, The Third Xiangya Hospital of Central South University, 410008 Changsha, Hunan, China, E-mail: mengjie@csu.edu.cn 